\title{
Glucose Uptake, Utilization, and Transfer by the Human Placenta as Functions of Maternal Glucose Concentration
}

\author{
S. HAUGUEL, V. DESMAIZIERES, AND J. C. CHALLIER \\ U. 166 INSERM, Maternité Baudelocque, [S.H.] and Université Pierre et Marie Curie, Biologie de la \\ Reproduction, Paris, France [V.D., J.C.C.]
}

\begin{abstract}
The impact of varying maternal glucose concentrations on glucose uptake, transfer, and metabolism was investigated in the human placenta perfused in vitro. The rates of placental glucose uptake from the maternal perfusate and transfer to the fetal perfusate were significantly correlated with maternal glucose concentration up to $20 \mathrm{mM}$. Placental glucose utilization was also dependent upon maternal glucose concentration up to $17 \mathrm{mM}$. Between 3 and $53 \mathrm{mM}$ maternal glucose, lactate production increased 3-fold while no change in oxygen consumption could be demonstrated. Correlatively, glucose storage was shown to increase dramatically above $10 \mathrm{mM}$ maternal glucose. These results suggest that glucose supply to the fetus may be limited in times of maternal hypoglycemia and that placental mechanism(s) may serve to buffer glucose transfer to the fetus in conditions of hyperglycemia. (Pediatr Res 20: 269-273, 1986)
\end{abstract}

Chronic changes in maternal glycemia (hypo or hyper) are known to alter fetal growth and development $(1,2)$. In the human, the contribution of the placenta to these perturbations is not fully understood. Although placental utilization and transfer of glucose have been studied for many years (3), data are still scarce. This is mainly due to the fact that the studies have been performed in vitro using different experimental procedures, such as placental tissue slices $(4,5)$, isolated microvilli $(6,7)$, or perfused placenta $(8,9)$. In some of these studies, metabolic characteristics were poorly controlled and the results displayed considerable variability. So far, most of the data concerning placental metabolism has been obtained from studies performed in vivo in the sheep (10-12). However, it is difficult to extrapolate the data collected in ruminant epitheliochorial placenta to the hemochorial human placenta. The present study was undertaken to determine whether changes in maternal glucose concentration could modify placental glucose metabolism and to what extent this could affect glucose supply to the fetus.

\section{MATERIALS AND METHODS}

Perfusion technique. Term human placentas were obtained from uncomplicated pregnancies after either vaginal delivery or caesarean section. The perfusion experiments were performed on an isolated lobule according to the method described by Panigel et al. (13), recently adapted for metabolic studies (14). The dual perfusions were carried out in open circuit using Earle's

Received June 3, 1985; accepted November 13, 1985.

Reprints S. Hauguel, U. 166 INSERM, Maternité Baudelocque, 123 Bld de Port-Royal, 75014 Paris, France. medium containing bovine serum albumin ( $\mathrm{g} /$ liter). The $\beta$-D $(+)$-glucose (Sigma, St Louis, MO) concentration in medium perfusing the fetal side was fixed at $2.8 \mathrm{mM}$. Glucose concentration in medium perfusing the maternal side varied from 2.8 to $53 \mathrm{mM}$. In some experiments $3-{ }^{3} \mathrm{H}-\mathrm{L}$-glucose $(10 \mathrm{mCi} / \mathrm{mmol}$, NEN, Paris, France) was added to arterial maternal perfusate to determine the diffusion rate of glucose.

Arterial perfusion fluids were continuously gassed with $95 \%$ $\mathrm{O}_{2}+5 \% \mathrm{CO}_{2}$. Flow rates were monitored with $\mathrm{R} 215$ A Brooks flowmeters and pressures were measured with mercury manometers (Boulitte, Paris, France) on fetal and maternal circulations.

Experimental protocol and sampling procedures. Within 30 min after delivery the main fetal artery and vein draining the selected lobule were cannulated. The experiments started $20 \mathrm{~min}$ after the onset of fetal perfusion when two cannulas were inserted into the intervillous space over the area blanched by perfusion of fetal circulation. The experiment lasted $120 \mathrm{~min}$. Fetal and maternal fluid samples were obtained every 5 or 10 min simultaneously on arterial and venous circulations for substrate determinations and gas measurements. As shown in Table 1, perfusion studies have been performed in a straight range of flow rates and cotyledon weights. Thus, homogenous experimental conditions were obtained between individual placentas.

Biochemical determinations. Samples for glucose and lactate determinations were collected on chilled perchloroacetic acid $(6 \%)$. Substrate concentrations were measured on protein-free supernatants neutralized with $\mathrm{KOH}$. Glucose was determined using glucose oxidase (God-Perid, Boehringer, Mannheim, Germany) and lactate according to the method of Hohorst (15). $\mathrm{PO}_{2}$ and $\mathrm{pCO}_{2}$ determinations were performed using a blood gas analyser (BMS 3 Mk2 Radiometer, Copenhagen, Denmark) on separate samples kept in air tight syringes at $4^{\circ} \mathrm{C}$.

Data analysis. From the data collected during the steady state period of each perfusion (four to eight individual determinations), the following calculations were performed: 1) glucose uptake: maternal $\mathrm{A}-\mathrm{V}$ concentration difference $\times$ flow rate; 2) glucose transfer: fetal V-A concentration difference $\times$ flow rate; 3) glucose utilization: glucose uptake-glucose transfer; 4) lactate production: maternal venous concentration $\times$ flow rate + fetal venous concentration $\times$ flow rate; 5) oxygen consumption: maternal $\mathrm{A}-\mathrm{V}$ concentration difference $\times$ flow rate + fetal $\mathrm{A}-\mathrm{V}$ concentration difference $\times$ flow rate.

The $\mathrm{O}_{2}$ concentration was calculated from the following relationship: $\mathrm{PO}_{2} \times 0.0239 / \mathrm{PB}-47 . \mathrm{PO}_{2}$ represents the oxygen partial pressure $(\mathrm{mm} \mathrm{Hg}), 0.0239$ the solubility of $\mathrm{O}_{2}$ in $\mathrm{ml} / \mathrm{ml}$ perfusate, $\mathrm{PB}$ the barometric pressure $(\mathrm{mm} \mathrm{Hg})$ and 47 the water vapor pressure $(\mathrm{mm} \mathrm{Hg})$ at $37^{\circ} \mathrm{C}$.

The glucose/oxygen quotient represents the maximal quantity of glucose that could be oxidized for a given oxygen consumption. Since $6 \mathrm{~mol}$ of $\mathrm{O}_{2}$ are required to completely oxidize $1 \mathrm{~mol}$ of glucose to $\mathrm{CO}_{2}$ and $\mathrm{H}_{2} \mathrm{O}$, the glucose/oxygen quotient is 
defined as:

$$
\mathrm{G} / \mathrm{O}_{2}=\frac{6 \times \text { glucose utilization }}{\mathrm{O}_{2} \text { consumption }}
$$

Concentrations were expressed in $\mu \mathrm{mol} / \mathrm{ml}$ and flow rates in $\mathrm{ml} / \mathrm{min} / \mathrm{g}$ of placenta. For each compound, the results were given in $\mu \mathrm{mol} / \mathrm{min} / \mathrm{g}$ of wet cotyledon weight.

The amount of glucose contributing to lactate production can be calculated from $\Delta \mathrm{L} / 2$ since the conversion of 1 mol of glucose gives 2 mol of lactate. The maximal amount of glucose oxidized was calculated as $\Delta \mathrm{O}_{2} / 6$. The amount of glucose which was not accounted for lactate production and oxygen consumption was defined as the maximal capacity of the placenta to store glucose. It was calculated by subtracting the maximal rate of glucose oxidized and the rate of lactate production from total glucose utilization.

Statistical methods. All values are given as mean $\pm \mathrm{SE}$. Linear or polynomial regression analysis using the method of least squares were used to analyze the relationships between various parameters using a Hewlett-Packard computer HP-41C.

\section{RESULTS}

Rate of placental glucose uptake as a function of maternofetal glucose concentration gradient. The relationship between placental glucose uptake and maternofetal glucose gradient is shown in Figure $1 A$. A significant correlation $(r=0.98, p<0.01)$ was found when the data were fitted to a cubic equation $\left(y=-0.69 \mathrm{x}^{3}\right.$ $\left.+1.46 \mathrm{x}^{2}-0.24 \mathrm{x}+0.01\right)$. The curve shows a saturable component at glucose gradient below $17 \mathrm{mM}$ and a nonsaturable component at glucose gradient higher than $17 \mathrm{mM}$. This threshold of maternofetal gradient corresponds to a maternal glucose concentration of $20 \mathrm{mM}$.

The nonsaturable component represents simple inward diffusion of substrate. This is demonstrated in Figure $1 A$ where uptake of $3{ }^{3} \mathrm{H}$-L-glucose is linearly correlated to glucose gradient (or

Table 1. Experimental conditions of perfusion*

\begin{tabular}{cccc}
\hline W & QM & QF & QF/QM \\
\hline $25.8 \pm 2.5$ & $24.0 \pm 0.5$ & $9.1 \pm 0.4$ & $0.38 \pm 0.02$
\end{tabular}

*W, cotyledon wet wt (g); QM, maternal arterial flow rate $(\mathrm{ml} / \mathrm{min})$; $\mathrm{QF}$, fetal arterial flow rate $(\mathrm{ml} / \mathrm{min})$. Values are means $\pm \mathrm{SE}$ of 12 experiments.

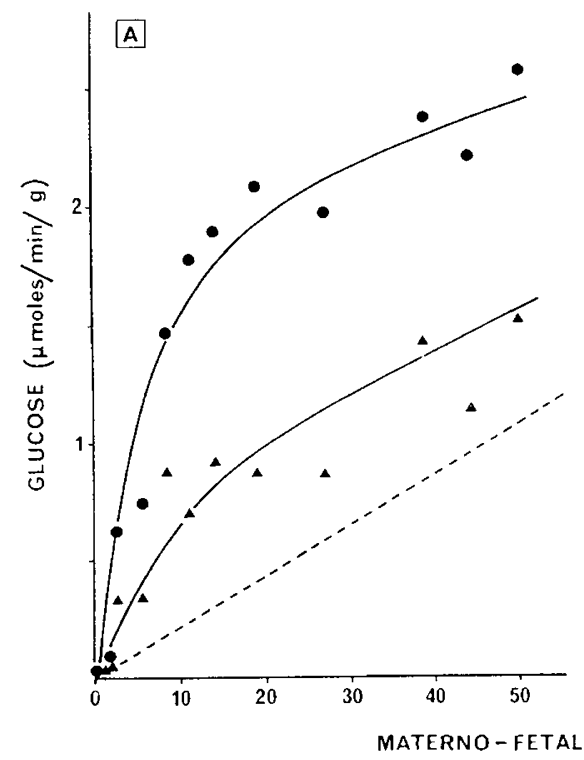

Fig. 1. A, glucose uptake $(\boldsymbol{\bullet})$ and transfer $(\boldsymbol{\Lambda})$ rates as a function of maternofetal glucose concentration gradient. Simple diffusion is represented by the straight line $(---)$, glucose uptake $(O)$ and transfer $(\Delta)$ rates corrected for diffusion. diffusional component. When the data were corrected for glucose diffusion, a maximal rate of $1.6 \mu \mathrm{mol} / \mathrm{min} / \mathrm{g}$ was obtained for glucose uptake (Fig. $1 B$ ).

Rate of placental glucose transfer as a function of maternofetal glucose concentration gradient. A significant correlation $(r=$ $0.92, p<0.01)$ between placental glucose transfer and maternofetal glucose gradient was obtained when the data were fitted to a cubic equation $\left(y=-0.29 x^{3}+0.64 x^{2}-0.11 x+0.01\right)$. As already observed for glucose uptake, the saturation started at 17 $\mathrm{mM}$ glucose gradient (i.e. $20 \mathrm{mM}$ maternal glucose). Transfer of $3-{ }^{3} \mathrm{H}$-L-glucose was also linearly correlated to glucose gradient (Fig. 1A). When the data were corrected for diffusion, the maximal rate of glucose transfer was $0.6 \mu \mathrm{mol} / \mathrm{min} / \mathrm{g}$ (Fig. $1 B$ ).

Kinetic characteristics of glucose uptake and transfer. The data corrected for diffusion conform to the Michaelis-Menten equation and apparent $\mathrm{Km}$ values can be calculated from LineweaverBurk plots. This analysis is shown in Figure 2. The $\mathrm{Km}$ values for glucose uptake and transfer were 17 and $13 \mathrm{mM}$, respectively.

Rates of placental glucose utilization as a function of maternal glucose concentration. The mean rate of placental glucose utilization has been calculated in each of the 10 experiments in steady state conditions. A significant correlation $\left(y=-0.39 x^{3}+\right.$ $\left.0.8 \mathrm{x}^{2}-0.12 \mathrm{x}+0.01 ; r=0.96 ; p<0.01\right)$ was observed between

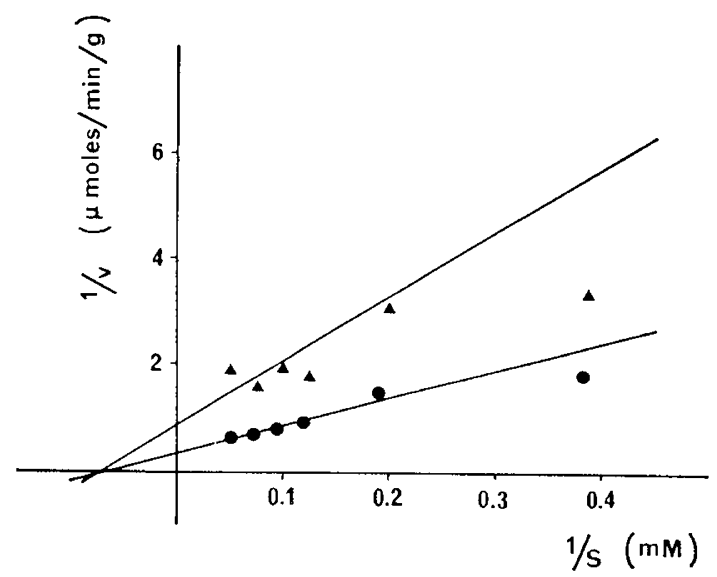

Fig. 2. Lineweaver-Burk plots of the data from Figure 1 corrected for diffusion. Glucose uptake: $\mathbf{0}$ Glucose transfer: $\boldsymbol{\Lambda}$

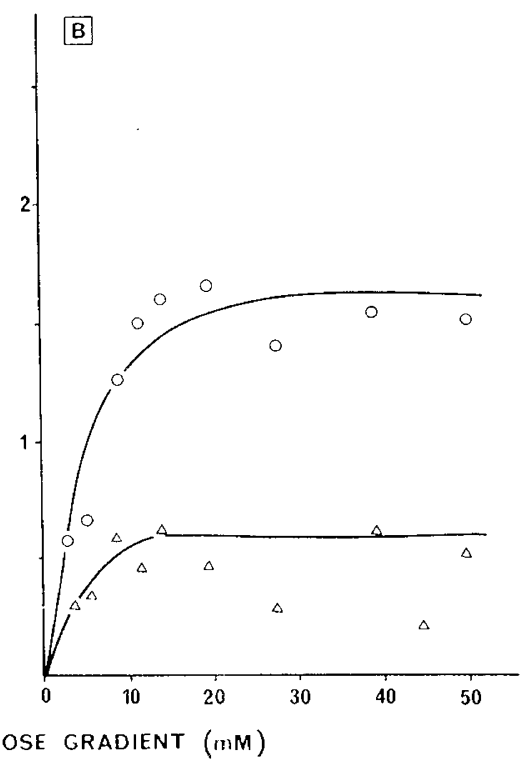

maternal concentration) and the straight line represents the 
placental glucose utilization and maternofetal concentration gradient using the method of least squares to calculate the regression. At maternal glucose concentration greater than $14 \mathrm{mM}$, the slope of the linear regression was not significantly different from zero $(p<0.5)$, indicating a maximal rate of glucose utilization by the placenta. This rate averaged $1.05 \pm 0.09 \mu \mathrm{mol} / \mathrm{min} / \mathrm{g}$ (Fig. 3).

Placental oxygen consumption, lactate production, and glucose/oxygen quotients. Oxygen consumption and lactate production by the placenta were measured in the same series of experiments. Oxygen consumption $(0.37 \pm 0.03 \mu \mathrm{mol} / \mathrm{min} / \mathrm{g})$ did not change when maternal glucose concentration increased from 3 to $53 \mathrm{mM}$. In contrast, lactate production increased from 0.12 \pm 0.03 to $0.48 \pm 0.01 \mu \mathrm{mol} / \mathrm{min} / \mathrm{g}$ when maternal glucose rose from 3 to $5.5 \mathrm{mM}$. A mean value of $0.40 \pm 0.06 \mu \mathrm{mol} / \mathrm{min} / \mathrm{g}$ was obtained for maternal glucose concentrations ranging between 5.5 and $53 \mathrm{mM}$. As shown in Figure 4, the quantity of glucose that could be maximally oxidized followed the same pattern as lactate production over the range of maternal concentration from 4 to $53 \mathrm{mM}$, while glucose storage (total glucose utilization minus glucose metabolized to lactate and maximal glucose oxidized) was increased from 0 to $70 \%$ of glucose utilization.
The $\mathrm{G} / \mathrm{O}_{2}$ quotients measured in each experiment are presented in Table 2 . These quotients have been corrected for lactate production and represent the maximal amount of glucose that could be oxidized per mmol of oxygen consumed by the placenta. The lowest quotient was 1.10 corresponding to $4 \mathrm{mM}$ maternal glucose.

\section{DISCUSSION}

Placental glucose uptake and transfer. The present study establishes the relationships that exist between placental glucose uptake from the maternal circulation, transfer to the fetal circulation and utilization, and maternal glucose concentration. The rates of glucose uptake and transfer were proportional to maternal glucose concentration up to $17-22 \mathrm{mM}$ for a maternofetal gradient of 14-19 mM. Above this value both glucose uptake and transfer rates appeared to be limited. Such a limitation of glucose transfer had also been reported for the human placenta in previous studies $(16,17)$ but at a much higher maternal glucose concentration than that found in the present study. The saturation begins for a maternofetal concentration gradient of 7-10

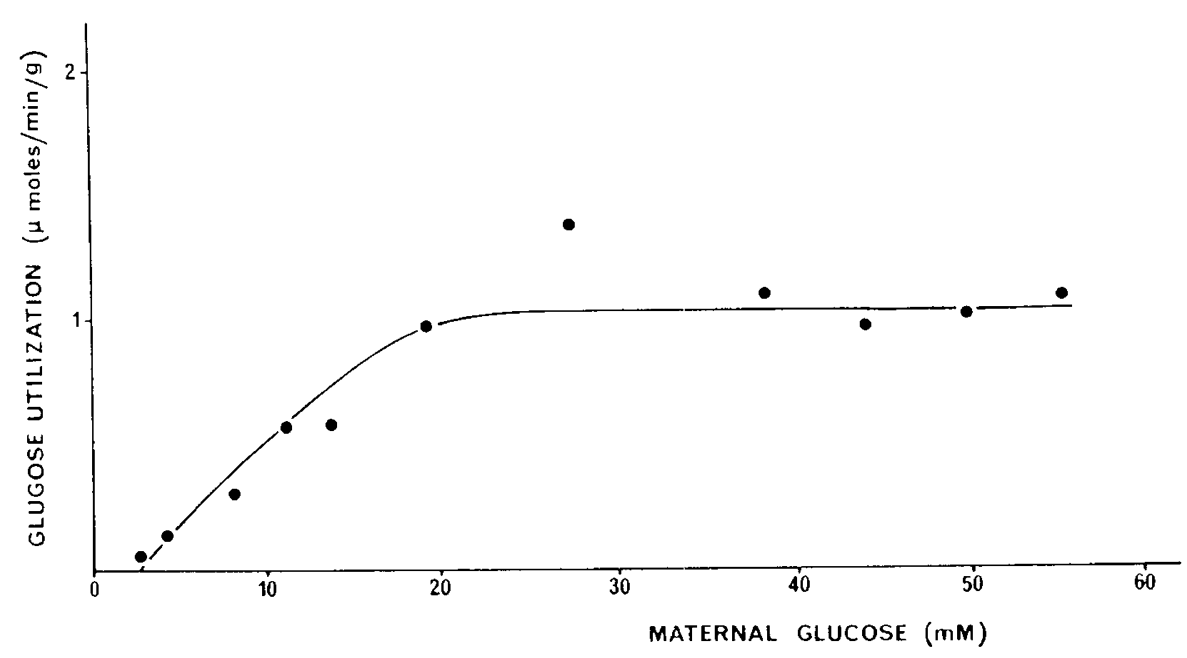

Fig. 3. Placental glucose utilization as a function of maternal glucose concentration.

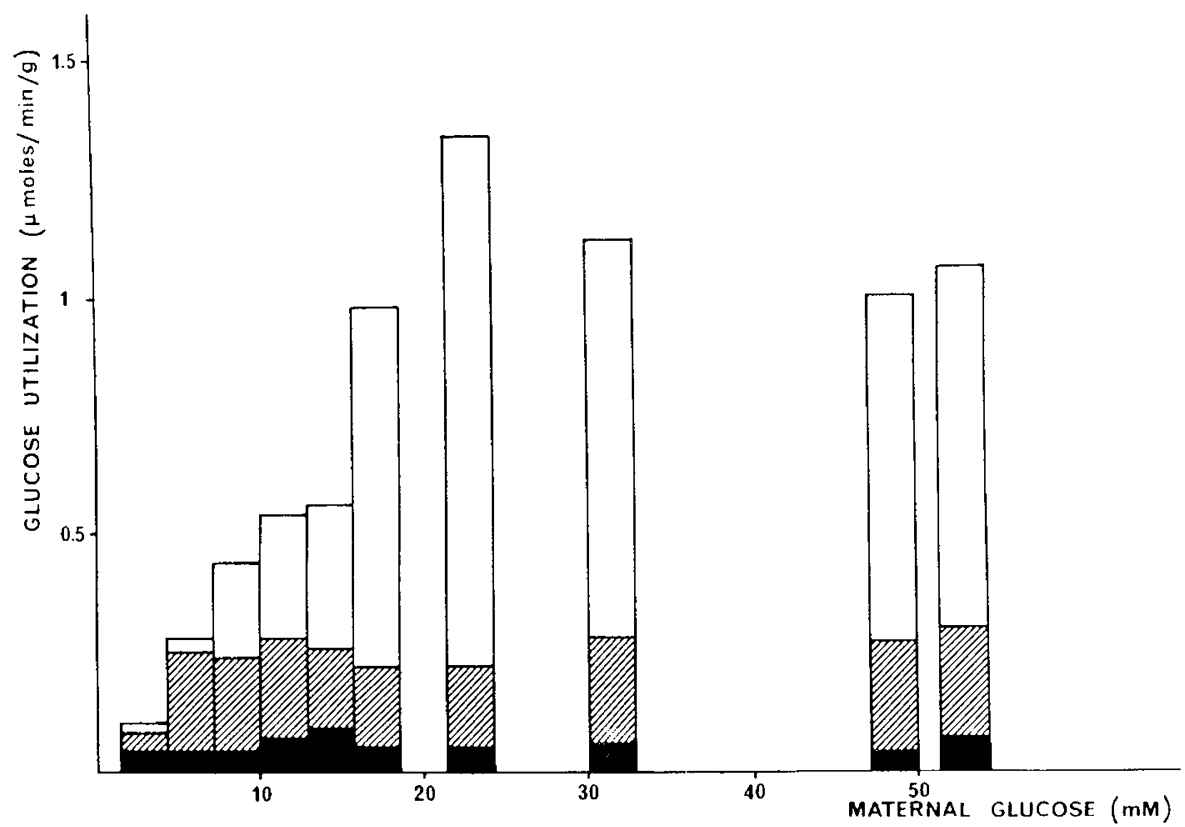

Fig. 4. Partition of placental glucose utilization as a function of maternal glucose concentration. Oxygen consumed for maximal glucose oxidation

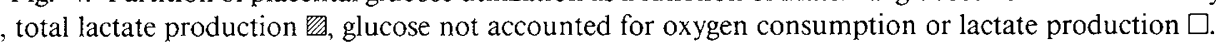


Table 2. Summary of glucose, lactate, and oxygen data*

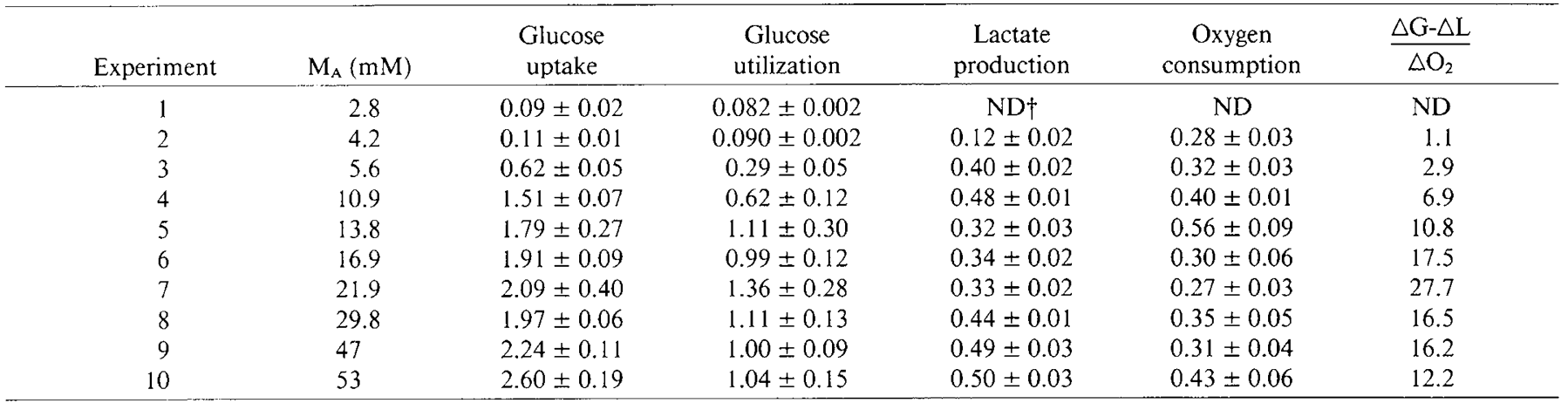

* MA, arterial glucose concentration in the maternal perfusate. All values are expressed in $\mu \mathrm{mol} / \mathrm{min} / \mathrm{g}$ except $\Delta \mathrm{G}-\Delta \mathrm{L} / \Delta \mathrm{O}_{2}$, which is a dimensionless quotient. $\Delta \mathrm{G}, 6 \times$ glucose utilization. $\Delta \mathrm{L}, 2 \times$ lactate production. $\Delta \mathrm{O}_{2}$, oxygen consumption.

$\dagger$ Not determined.

$\mathrm{mM}$ at a maternal arterial glucose concentration of $39-50 \mathrm{mM}$ in closed circuits (17); while in open circuits (16) it begins at a maternofetal gradient of $38 \mathrm{mM}$ (the maternal concentration achieved was not indicated). This discrepancy with our results could be due to the different methodology used by these authors. Indeed, in their experiments, maternal glucose concentration rose continuously so that the measurements could not be made under steady state conditions and thus led to inaccurate values. In addition, mean values for saturation were obtained from two or three placentas only. In the present experiments, maternal glucose concentration was maintained at constant value during the whole perfusion ensuring steady state measurements. The kinetics of glucose uptake by the human placenta have never been studied previously simultaneously with glucose transfer. Our results show that the placenta has a limited capacity to take up glucose from maternal circulation and that this limitation is coupled with that of transfer. The apparent threshold of $17 \mathrm{mM}$ is well above physiological glucose levels; even in diabetic pregnancies such high levels of blood glucose are rarely encountered since such patients are now generally well controlled.

The data from Figure 1 show that the diffusion process was not negligible in these studies and that it represents $40 \%$ of total uptake at $53 \mathrm{mM}$ maternal glucose. This is in agreement with the data provided by Schneider et al. (9) and Carstensen et al. (16) who found a diffusion of 30 and $70 \%$, respectively, depending on the maternofetal glucose gradient. By contrast, Johnson and Smith (18) found this phenomenom to be negligible in microvillous vesicles prepared from human placenta. The rate of placental glucose transfer measured in our studies at normal maternal glucose concentration is $0.29 \pm 0.03 \mu \mathrm{mol} / \mathrm{min} / \mathrm{g}$ placenta and corresponds to a maximal glucose utilization by the fetus of $150 \mu \mathrm{mol} / \mathrm{min}$ for a $500 \mathrm{~g}$ placenta, i.e. $43 \mu \mathrm{mol} / \mathrm{min} /$ $\mathrm{kg}$ fetus for a $3.5 \mathrm{~kg}$ fetus. This value is slightly higher than the value estimated in vivo (19) of $38 \mu \mathrm{mol} / \mathrm{min} / \mathrm{kg}$ fetus at a maternal glucose concentration of $5.5 \mathrm{mM}$.

Kinetic characteristics of glucose transport. Kinetic characteristics of the glucose transport system can only be determined when total saturation is achieved, i.e. when data have been corrected for simple diffusion. Under these conditions glucose uptake and transfer have similar $\mathrm{Km}$ of $13-17 \mathrm{mM}$. This value is 3-fold higher than the normal maternal blood glucose concentration, indicating that the glucose transport sites are never saturated under in vivo physiological conditions and that glucose transport is not a limiting factor for glucose supply to the fetus.

To our knowledge this is the first study in which $\mathrm{Km}$ values were simultaneously measured for glucose uptake and transfer in conditions that conserve the cellular integrity of the placenta in contrast to the situation with microvillous preparations. Johnson and Smith (18) have reported a slightly higher Km value for the glucose analog, 3-O-methylglucose $(24$ or $31 \pm 13 \mathrm{mM})$. More recently, these authors have demonstrated that the char- acteristics of the glucose transport system across the basal membrane of placental syncytium (fetal-facing) are similar to those of the microvillous membrane on the opposite side of the syncytium (maternal-facing) (7). These data are in accord with the present results indicating that glucose transport kinetics for uptake and transfer are comparable. Similar findings have also been reported for the guinea pig placenta. Yudilevitch et al. (20) found that the glucose transport system on the maternal and the fetal sides of the trophoblast have the same kinetic characteristics, and Bissonnette (21) demonstrated a $\mathrm{Km}$ value of $12 \mathrm{mM}$. An equivalent observation has also been reported for the sheep placenta studied in vivo (22). In this report the authors have made the assumption that there is a negligible glucose gradient within the cell and that the carriers on both sides of the placenta have the same $\mathrm{Km}$ of $3.8 \mathrm{mM}$. The maximal rate of glucose transport has also been quantified, and averages $2.2 \mu \mathrm{mol} / \mathrm{min} / \mathrm{g}$ for uptake (Fig. 2). It is two times lower than the value estimated in placental microvilli in vitro, i.e. $1.9 \mathrm{mmol} / \mathrm{min}$ for the whole placenta (6).

Placental glucose metabolism. As observed for glucose uptake and transfer, placental glucose utilization rate is proportional to maternal glucose concentration (Fig. 3) until 17-22 mM and always represents 50 to $60 \%$ of total glucose uptake by the placenta. Thus, we cannot conclude from these results whether the saturation of glucose utilization above this concentration is the consequence of the limited uptake at this concentration or a concomitant limitation of several steps in the pathway of glucose utilization. The onset of saturation observed in our experiments is twice as high than that observed in other perfusion studies (8) in which the maximal rate of glucose utilization was $0.12 \mu \mathrm{mol} /$ $\mathrm{min} / \mathrm{g}$, i.e. a value 10 -fold lower than that obtained in the present study $(1.0 \mu \mathrm{mol} / \mathrm{min} / \mathrm{g})$. The placental oxygen consumption of $0.37 \mu \mathrm{mol} / \mathrm{min} / \mathrm{g}$ measured at $5.5 \mathrm{mM}$ maternal glucose is two to three times lower than that reported in the sheep uteroplacenta in vivo (11), $0.89 \mu \mathrm{mol} / \mathrm{min} / \mathrm{g}$. However it is of the same order of magnitude of values measured in the fetoplacental unit of the rabbit (23) and the cow (24). Although previous studies have shown that the conditions of oxygenation used in our perfusions are within the physiological range $(14,25)$, we still should consider the possibility that the oxygen consumption had been physically limited in our experiments. In maternal physiological conditions ( 4 to $7 \mathrm{mM}$ arterial glucose), the maximal proportion of glucose which is retained, but not metabolized, within the placenta is very small but increases dramatically during maternal hyperglycemia (Fig. 4). These findings agree with the enhanced glycogen and lipid deposition found in placentas from diabetic mothers $(26,27)$. The very high $\mathrm{G} / \mathrm{O}_{2}$ quotients measured under conditions of marked hyperglycemia (Table 2 ) also suggest that the maximal capacity of the placenta to oxidize glucose becomes rapidly saturated, as does total lactate production when maternal glucose concentration increases.

The relative glucose utilization by the fetoplacental unit and 
nonuterine maternal tissues can be calculated from the present in vitro data and should be regarded as only an estimation of the in vivo situation. At $5.5 \mathrm{mM}$ maternal glucose, the maximal rate of glucose uptake by the placenta is $310 \mu \mathrm{mol} / \mathrm{min}$ of which $50 \%$ are readily transferred to the fetal circulation and $50 \%$ retained within the placenta (Fig. 1, Table 2). Using a glucose turnover rate of $880 \mu \mathrm{mol} / \mathrm{min}$ for a $65 \mathrm{~kg}$ pregnant woman at term (19), it can be assumed that about $35 \%$ of maternal glucose production would be diverted to the fetoplacental unit while the remaining $65 \%$ would possibly be utilized by nonuterine maternal tissues. It is of interest that this estimated value is in the range of the partition of maternal glucose production between the conceptus and nonuterine maternal tissues observed in the pregnant sheep in vivo (11).

In conclusion, this study has demonstrated that glucose supply to the fetus is highly dependent upon maternal glycemia between 3 and $20 \mathrm{mM}$. Thus the supply of glucose to the fetus is likely to be diminished in the case of maternal hypoglycemia and to be increased in the case of maternal hyperglycemia (diabetes), conditions known to affect fetal growth. In addition, these data provide evidence suggesting that the placenta possesses a compensatory mechanism (i.e. a large capacity for glucose storage) that blunts glucose transfer to the fetus when maternal hyperglycemia prevails.

Acknowledgments. The authors thank Dr. J. Girard for his helpful comments in reviewing this paper. Mrs. M. Verger and M. T. Robin are acknowledged for preparing the manuscript.

\section{REFERENCES}

1. Gruppuso PA, Migliori R, Susa JB, Scwartz R 1981 Chronic maternal hyperinsulinemia and hypoglycemia. A model for experimental intrauterine growth retardation. Biol Neonate 40:113-120

2. Knopp RH, Montes A, Childs M, Li JR, Mabuchi H 1981 Metabolic adjustments in normal and diabetic pregnancy. Clin Obstet Gynecol 24:21-48

3. Chinard S, Danesino V, Hartman WF, Huggett ASG, Paul W, Reynolds SRM 1956 The transmission of hexoses across the placenta in the human and rhesus monkey. J Physiol 132:289-292

4. Holzman IR, Philipps AF, Battaglia FC 1979 Glucose metabolism, lactate and ammonia production by the human placenta in vitro. Pediat Res 13:117120

5. Villee CA 1953 The metabolism of human placenta in vitro. J Biol Chem 205:113-121

6. Smith CH, Nelson DM, King BF, Donohue TM, Ruzycki SM, Kelley LK 1977 Characterization of a microvillous membrane preparation from human placental syncytiotrophoblast: a morphologic, biochemical, and physiologic study. Am J Obstet Gynecol 128:190-196
7. Johnson LW, Smith CH 1985 Glucose transport across the basal plasma membrane of human placental syncytiotrophoblast. Biochim Biophys Acta 815:44-50

8. Nesbitt REL, Rice PA, Rourke JE 1973 In vitro perfusion studies of the human placenta. III. The relationships between glucose utilization rates and concentrations. Gynecol Invest 4:243-253

9. Schneider H, Challier JC, Dancis J 1981 Transfer and metabolism of glucose and lactate in the human placenta studied by a perfusion system in vitro. Placenta 2(suppl):129-135

10. Hay WW, Sparks JW, Wilkening RB, Battaglia FC, Meschia G 1983 Partition of maternal glucose production between conceptus and maternal tissues in sheep. Am J Physiol 245:E347-E350

11. Meschia G, Battaglia FC, Hay WW, Sparks JW 1980 Utilization of substrates by the ovine placenta in vivo. Fed Proc 39:245-249

12. Morriss FH 1981 Placental factors conditioning fetal nutrition and growth. Am J Clin Nutr 34:760-768

13. Panigel M, Pascaud M, Brun JL 1985 Une nouvelle technique de perfusion de l'espace intervilleux dans le placenta humain isolé. Pathol Biol 15:821

14. Hauguel S, Challier JC, Cedard L, Olive G 1983 Metabolism of the human placenta perfused in vitro: glucose transfer and utilization, lactate and ammonia production. Pediatr Res 17:729-732

15. Hohorst HJ 1963 Lactate determination with lactic dehydrogenase. In: Bergmeyer HU (ed) Methods of Enzymatic Analysis. Academic Press, New York pp 266-270

16. Carstensen M, Leichtweiss HP, Molsen G, Schröder H 1977 Evidence for a specific transport of $\mathrm{D}$-hexoses across the human term placenta in vitro. Arch Gynäk 222:197-198

17. Rice PA, Rourke JE, Nesbitt REL 1976 In vitro perfusion studies of the human placenta. IV. Some characteristics of the glucose transport system in the human placenta. Gynecol Invest 7:213-221

18. Johnson LW, Smith CH 1980 Monosaccharide transport across microvillous membrane of human placenta. Am J Physiol 238:C160-C168

19. Kalhan SC, D'Angelo LJ, Savin SM, Adam PAJ 1979 Glucose production in pregnant women at term gestation. Sources of glucose for human fetus. J Clin Invest 63:388-394

20. Yudilevitch DL, Eaton BM, Short AH, Leichtweiss HP 1979 Glucose carriers at maternal and fetal sides of the trophoblast in guinea pig placenta. Am J Physiol 237:C205-C212

21. Bissonnette JM 1981 Studies in vivo of glucose transfer across the guinea pig placenta. Placenta 2(suppl):155-162

22. Simmons MA, Battaglia FC, Meschia G 1979 Placental transfer of glucose. J Dev Physiol 1:227-243

23. Gilbert M, Hauguel S, Bouisset M 1984 Uterine blood flow and substrate uptake in conscious rabbit during late gestation. Am J Physiol 247:E574E580

24. Silver M, Comline RS 1976 Fetal and placental $\mathrm{O}_{2}$ consumption and the uptake of different metabolites in the ruminant and horse during late gestation. In: Reneau DD, Grote $\mathbf{J}$ (eds) Oxygen Transport to Tissue, Symposium II, Vol 75. Plenum Press, New York, pp 731-736.

25. Challier JC, Schneider H, Dancis J 1976 In vitro perfusion of human placenta. V. Oxygen consumption. Am J Obstet Gynecol 126:261-265

26. Gabbe SG, Demers LM, Greep RO, Villee CA 1972 Placental glycogen metabolism in diabetes mellitus. Diabetes 21:1185-1191

27. Diamant YZ, Kissilevitz R 1983 Metabolic changes in human placental tissue in diabetes mellitus. In: Miller RK, Thiede HA (eds) Trophoblast Research, Vol 1. Plenum Press, New York, pp 209-222 